Article

\title{
Experimental Investigation of Crack Extension Patterns in Hydraulic Fracturing with Shale, Sandstone and Granite Cores
}

\author{
Jianming $\mathrm{He}^{1}$, Chong $\mathrm{Lin}^{1,2, *},{\mathrm{Xiao} \mathrm{Li}^{1}}^{1}$ and Xiaole Wan ${ }^{1,2}$ \\ 1 Key Laboratory of Shale Gas and Geoengineering, Institute of Geology and Geophysics, \\ Chinese Academy of Sciences, Beijing 100029, China; hjm@mail.iggcas.ac.cn (J.H.); \\ lixiao@mail.iggcas.ac.cn (X.L.); 15201018179@163.com (X.W.) \\ 2 College of Earth Science, University of Chinese Academy of Sciences, Beijing 100049, China \\ * Correspondence: linc0616@163.com; Tel.: +86-10-8299-8653
}

Academic Editor: Alireza Bahadori

Received: 7 October 2016; Accepted: 23 November 2016; Published: 1 December 2016

\begin{abstract}
Hydraulic fracturing is an important method of reservoir stimulation in the exploitation of geothermal resources, and conventional and unconventional oil and gas resources. In this article, hydraulic fracturing experiments with shale, sandstone cores (from southern Sichuan Basin), and granite cores (from Inner Mongolia) were conducted to investigate the different hydraulic fracture extension patterns in these three reservoir rocks. The different reactions between reservoir lithology and pump pressure can be reflected by the pump pressure monitoring curves of hydraulic fracture experiments. An X-ray computer tomography (CT) scanner was employed to obtain the spatial distribution of hydraulic fractures in fractured shale, sandstone, and granite cores. From the microscopic and macroscopic observation of hydraulic fractures, different extension patterns of the hydraulic fracture can be analyzed. In fractured sandstone, symmetrical hydraulic fracture morphology could be formed, while some micro cracks were also induced near the injection hole. Although the macroscopic cracks in fractured granite cores are barely observed by naked eye, the results of X-ray CT scanning obviously show the morphology of hydraulic fractures. It is indicated that the typical bedding planes well developed in shale formation play an important role in the propagation of hydraulic fractures in shale cores. The results also demonstrated that heterogeneity influenced the pathway of the hydraulic fracture in granite cores.
\end{abstract}

Keywords: hydraulic fracture; anisotropy; heterogeneity; crack extension; fracture distribution

\section{Introduction}

Compared with other fossil fuels, shale gas is a cleaner and more sufficient resource. It will continue to reduce the overdependence on high-energy consumption and high-pollution discharge resources, offering more options for reducing air pollutants and greenhouse gas emissions. In addition, Enhanced Geothermal System (EGS)—formerly known as Hot Dry Rock (HDR) - is a technology used to exploit geological heat resources in non-volcanic regions where the natural permeability of rock formations is extremely low. It provides inspiring prospects in terms of producing large quantities of energy from deep underground rocks [1]. Hydraulic fracturing is a key technology in the exploitation and stimulation of tight sand gas, shale gas, and geothermal resources. The mechanisms of generating complex fracture networks are of vital importance for hydraulic fracturing treatment. Hydraulic fracture propagation in these reservoirs is complicated due to the coupled process of mechanical deformation, fluid flow, potential heat transfer, and complex conditions such as offsets, jogs, and preexisting natural fractures. The aims of hydraulic fracturing operation are hydro-fracturing (creating new fractures and reopening the pre-existing natural fractures) and hydro-shearing (making 
the slip of pre-existing fractures associated with shear dilation). This process creates new hydraulic fractures and reactivates existing natural fractures, forming a stimulated reservoir volume (SRV) with a high permeability.

In recent decades, a series of laboratory experiments and field tests have been conducted to study the hydraulic fracturing process [2-10]. In addition, some key experimental factors such as horizontal in situ stress difference, rock brittleness, viscosity, and injection rate of fracturing fluid have been investigated by some researchers [11-14]. However, these studies mainly focused on the interactions between hydraulic fractures and geological discontinuities such as natural fractures or the effects of experimental factors on the fracturing results. A rock is typically heterogeneous because it contains initial defects such as micro-cracks, pores, and grain boundaries, or the laminated structure. Scholz [15] proposed that the heterogeneity leads to local stresses in a stressed rock, and the magnitudes may deviate significantly from that of the applied stress. Renard [16] studied the 3D imaging of hydraulic fracture propagation in limestone cores using synchrotron X-ray microtomography. The results showed that hydraulic fracturing was propagated by the linkage of the pores. Chitrala et al. [17] demonstrated the effects of bedding and the magnitude of anisotropy of reservoir rocks on the fracture propagation direction. Stanchits [18] observed that the propagation of the cloud of acoustic emission induced by hydraulic fracture was faster in the direction parallel to bedding than perpendicular to it. According to a study by Brenne and Molenda [19], the breakdown pressures of six rock types were extremely different under the same experimental conditions. Li et al. [20] conducted hydraulic fracturing experiments in shale cores with different stress statuses using different stimulating fluids, such as $\mathrm{H}_{2} \mathrm{O}, \mathrm{CO}_{2}$, and $\mathrm{N}_{2}$. The correlations of the specific properties of these three stimulating fluids were obtained. Pradhan et al. [21] investigated stress-induced fracturing in sandstone and limestone cores by acoustic monitoring and $\mu \mathrm{CT}$ image analysis to reveal the fracture patterns. Shao et al. [22] investigated the significant effects of a larger aperture on the propagation of hydraulic fractures in granite cores. In addition, they conducted CFD modeling based on X-ray microtomography (XMT) analysis. Zhu et al. performed numerical simulation for the modelling of crack propagation evolving from micro-structures [23]. Zhuang and Ren [24,25] developed a dual-horizon peridynamics (DH-PD) method and Coupled Thermo-Hydro-Mechanical Model to investigate the behavior of crack propagation in reservoir rocks. These aforementioned studies indicated the differences in the fracturing process between different rock types. It is obvious that the patterns of hydraulic fracture propagation in different reservoir formations are different. The initial structure of rock has a powerful influence on the initiation and propagation of hydraulic fractures in reservoir rocks. The laminated structures in shale can result in the typical transverse isotropic mechanical behavior, so it is obvious that it can affect the pathway of hydraulic fractures in shale formations. The heterogeneity of granite formations also can influence the propagation of hydraulic fractures. Therefore, there is much more room for the improvement in our knowledge and understanding of the mechanisms of the propagation of hydraulic fractures in different rock formations.

In this study, a series of procedures were designed to study the different crack extension patterns of hydraulic fracturing in sandstone, shale, and granite cores under the same stress conditions and injection rates. Firstly, P wave velocities of sandstone, shale, and granite core samples were measured for the comparison of the three different reservoir rocks. Then, an injection hole was drilled in the middle of every rock core sample. Thirdly, the hydraulic fracturing experiments were conducted on these drilled cores by injecting the water into the hole. Finally, an X-ray computer tomography (CT) scanning machine was employed to obtain the spatial distribution of the hydraulic fractures in these fractured specimens. In this paper, the results of hydraulic fracturing experiments can be summarized as follows: (a) as a reference, hydraulic fracturing experiments of sandstone specimens were conducted; (b) the influences of anisotropic characteristics of shale and the heterogeneity of granite on the propagation of hydraulic fractures were investigated; (c) different crack extension patterns in these three different rocks were discussed. 


\section{Experimental Methodology}

\subsection{Sample Preparation}

As a common and practical way to investigate the mechanisms of the formation of hydraulic fractures, laboratory experiments provide a more visual way to observe the fracture geometry with better control of boundary conditions. In our experimental design, hydraulic fracturing experiments were conducted with sandstone, shale, and granite cores to investigate the differences of crack extension patterns in these three reservoir rocks. The depth of the formations to be hydraulically fractured is usually thousands of meters, so proper retrieval of shale cores is sometimes impossible and quite costly for the limitation of drilling technology. In addition, the size of the cores may also be too small to meet the requirements of the experimental apparatus. Therefore, the shale samples were taken from the outcrops of the Longmaxi formation in Chongqing, China. The formation is black and deep black carbonaceous shale with a parallel interaction of thin layers and thick layers. The bedding planes are well developed with a dip angle of $70^{\circ}$. The interlayer bonding force is relatively low. To ensure the integrity of the shale samples, after the removal of the weathered surface layer, shale blocks with a size of $400 \mathrm{~mm} \times 400 \mathrm{~mm} \times 400 \mathrm{~mm}$ were taken for the coring of shale samples. The granite cores were drilled $500 \mathrm{~m}$ under the surface in Inner Mongolia. To study the effects of anisotropy on the hydraulic fracture propagation in shale and granite cores, hydraulic fracturing experiments were performed on the cylindrical sandstone, shale, and granite cores measuring $90 \mathrm{~mm}$ in height and $50 \mathrm{~mm}$ in diameter. All the core specimens, including sandstone, shale, and granite cores were drilled with $50 \mathrm{~mm}$ water cooled diamond core drills. Core end planes were cut with a water flushed diamond saw blade and ground coplanar to a maximum deviation of $\pm 0.02 \mathrm{~mm}$. The shale samples were drilled from the outcrop blocks in the different bedding plane angles of $0^{\circ}, 30^{\circ}, 45^{\circ}, 60^{\circ}, 90^{\circ}$ respectively. The bedding plane angle means the angle between the coring direction and bedding plane. Because the sedimentary planes are clearly observed on the surfaces of the blocks, the intersection angles between the drilling direction and the bedding plane were easily located. Figure 1 shows the diagram of the drilled the shale core with different bedding plane angles. A hole with a diameter of $8 \mathrm{~mm}$ for the injection of hydraulic fracturing was drilled along the central axis of each cylindrical sample from the top to the bottom of the specimen to simulate the borehole.

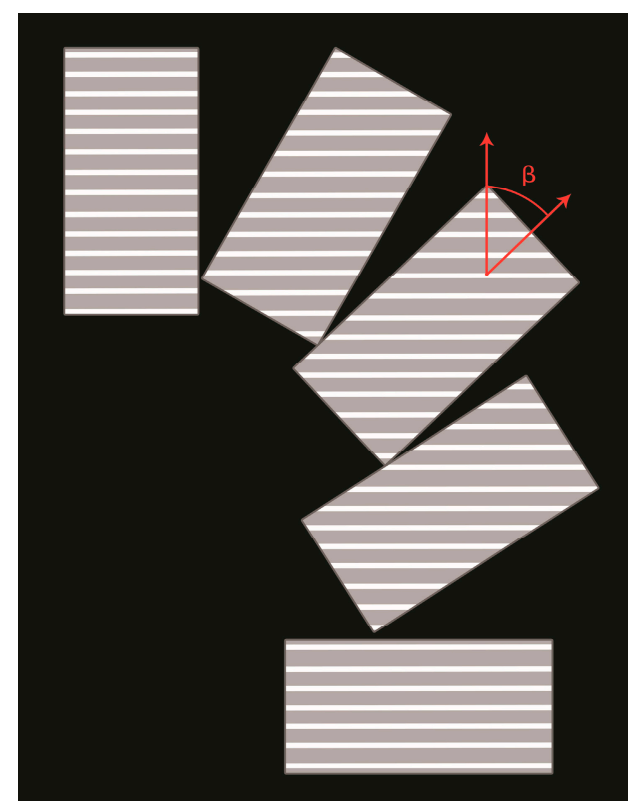

Figure 1. Schematic diagram of shale coring. 


\subsection{Experimental Procedure}

The hydraulic fracturing experiments reported here were conducted employing the GCTS RTX-3000 tri-axial rock testing system in Tongii University, China. The testing system consists of a hydraulic station, a microprocessor, a loading rack, a pressure chamber, confining pressure, and a pore pressure supercharger. The triaxial loading system allows for triaxial loading of rock specimens along with simultaneous injection of fracturing fluid. The axial stress is applied using a piston mounted inside the confining vessel by control of deviator stress. Confining pressure is applied using the confining fluid (hydraulic oil). A series of experimental hydraulic fracturing tests were carried out in thick walled, hollow cylinders of sandstone, shale, and granite cores with an external diameter of $50 \mathrm{~mm}$, a length of $90 \mathrm{~mm}$, and a central hole whose diameter is $8 \mathrm{~mm}$. Specimens were placed in a tri-axial pressure chamber and subjected to predetermined stress conditions (confining pressure $\mathrm{P}_{\text {conj }}=20 \mathrm{MPa}$ : representing uniform horizontal stress, vertical load $\sigma_{\mathrm{v}}=25 \mathrm{MPa}$ : simulating vertical far-field stress and uniform fluid pressure). Figure 2 shows the specimens installed in the testing system. During the entire test, constant oil confinement of $20 \mathrm{MPa}$ was exerted on an impermeable sleeve, and an O-ring was used on the top of the specimen to ensure sealing of the connection and to avoid any communication between the external fluid (oil) used to apply the desired confining pressure and the internal volume in the rock core during the hydraulic fracturing experiment.

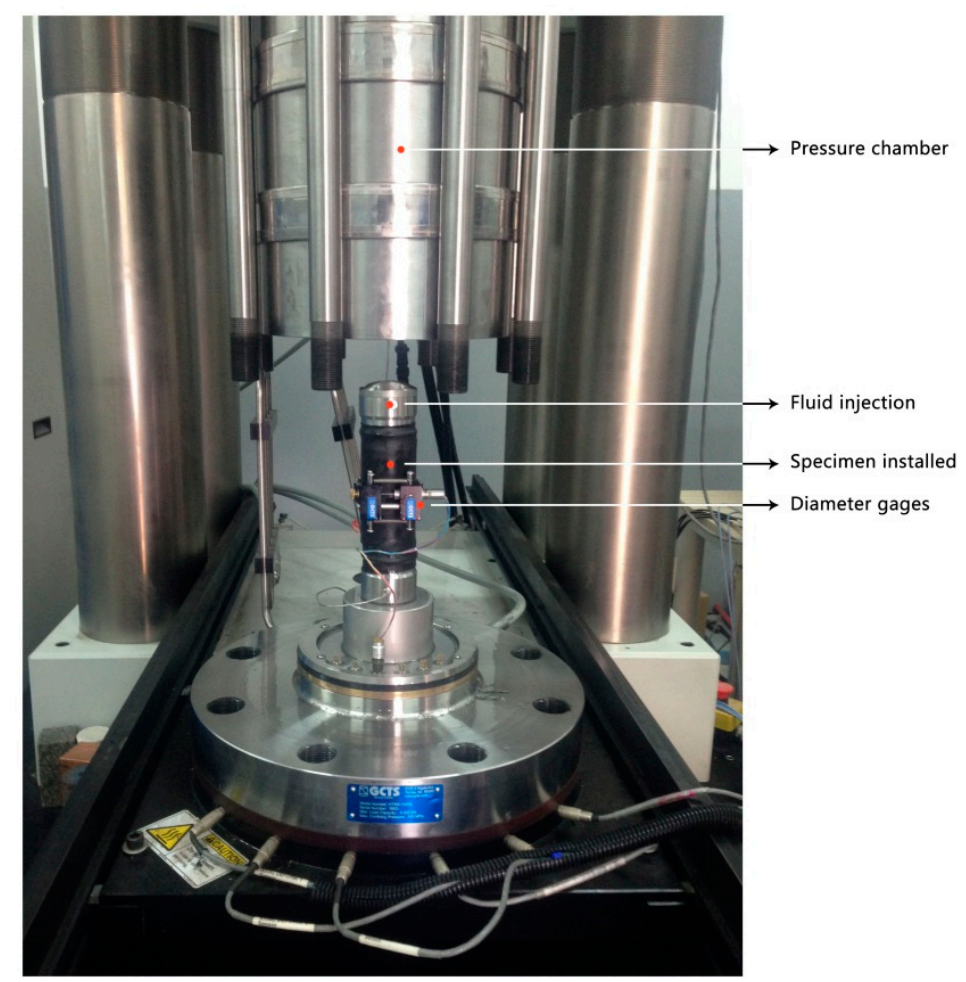

Figure 2. Photo of experimental devices installed.

The procedures of the hydraulic fracturing experiment were set to five steps. The first step involved increasing confining pressure to the target level with a rate of $0.1 \mathrm{MPa} / \mathrm{s}$. The next step involved increasing the axial stress to the target stress at a rate of $0.2 \mathrm{MPa} / \mathrm{s}$ by controlling the deviator stress. Thereafter, the stress status was kept constant for five minutes. This was followed by injecting water at a constant rate into the specimen through the drilling hole. Finally, in order to reach the equilibrium state of the whole experimental system, the constant injection would last one more minute after the specimen was fractured. During the experimental procedure, all the data including the axial stress, confining pressure, pump pressure, and radial displacement were recorded every $0.1 \mathrm{~s}$. The jacketed sample was placed in the loading vessel of the apparatus, and confining and axial pressure 
were applied in sequence. Once the desired stress state was achieved, the axial stress was held as constant and the pump, which controlled the confining pressure, was set to a constant volume. Because the confining pressure pump was kept at a constant volume, a rapid increase of confining pressure can also be a sign of sample failure.

\section{Results and Discussion}

\subsection{Characteristics of Rock Materials}

Wave velocity is a typical characteristic of rock materials. In this article, the P wave velocity of each rock specimen was measured before the injection hole was drilled. The results of the $P$ wave velocity measurements are shown in Figure $3 a, b$. The $P$ wave velocity of each rock core sample was measured along the vertical direction. The average $P$ velocity for each kind of rock samples was obtained. The curve in Figure 3a,b shows the average P wave velocity of the sandstone, shale (for each bedding plane angle), and granite cores. The smaller points represent the $\mathrm{P}$ wave velocity of each sample, the bigger points present the average $P$ wave velocity of each sample group.

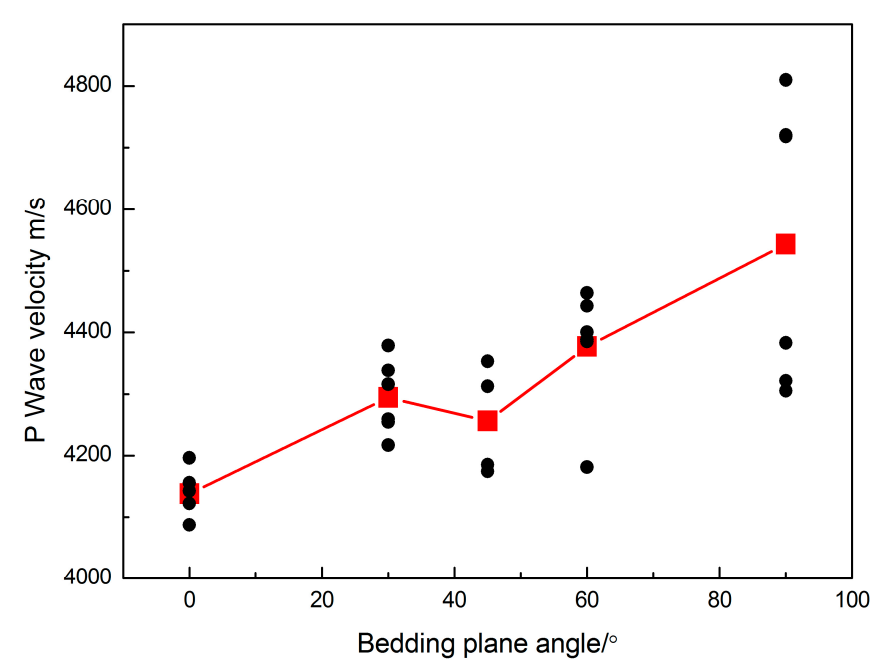

(a)

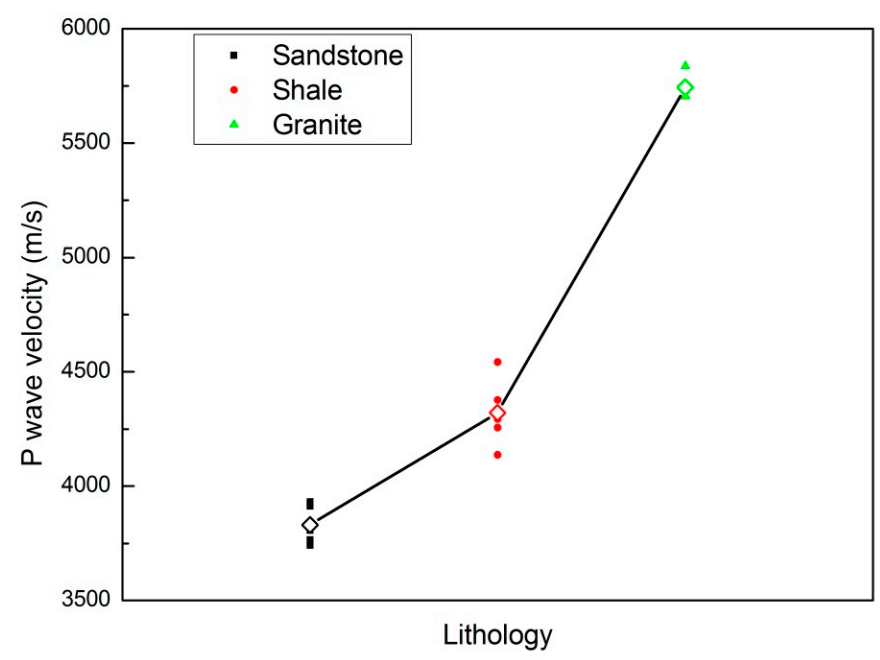

(b)

Figure 3. (a) The $\mathrm{P}$ wave velocity of each shale specimen was measured in the vertical direction. Note that the velocities of shale cores were measured with five bedding plane angles $\left(0^{\circ}, 30^{\circ}, 45^{\circ}, 60^{\circ}\right.$, $90^{\circ}$ ) for the investigation of anisotropy result from sedimentary structure; (b) Comparison of P wave velocities of sandstone, shale, and granite cores. 
The orthogonal isotropy due to the sedimentary bedding planes of shale is clearly shown in Figure 3a. According to the tests results, the $\mathrm{P}$ wave of the specimen nearly increased with the increase of the bedding plane angle of the samples. The average value of $\mathrm{P}$ wave velocity of the specimens whose bedding angle is $90^{\circ}$ is $4543 \mathrm{~m} / \mathrm{s}$. While the average $\mathrm{P}$ wave velocity of those samples whose bedding plane angle is $0^{\circ}$ is $4138 \mathrm{~m} / \mathrm{s}$. It is quite lower than that of the samples whose bedding plane angle is $90^{\circ}$. From the results of $\mathrm{P}$ wave ultrasonic tests of shale cores, according to the research by Mighani et al. [26], the degree of anisotropy can be defined as

$$
D_{a}=\frac{V_{\max }-V_{\min }}{V_{\max }}
$$

The measured anisotropy of shale specimens is about $9 \%$, making the anisotropy of shale formation obvious. The anisotropy of shale formation is induced by its laminated structure. The results of the P wave measurements of shale cores have good consistency with the tests of Vernik [27]. The average value of $P$ wave velocity for sandstone and granite cores is about $3831 \mathrm{~m} / \mathrm{s}$ and $5744 \mathrm{~m} / \mathrm{s}$, respectively. According to the results, the $\mathrm{P}$ wave velocity of sandstone cores is the lowest one among these three rock materials, while that of the granite core is highest.

In addition, the CT scanning tests were conducted before the hydraulic fracturing experiments. Figure $4 \mathrm{a}-\mathrm{c}$ shows the CT scanning results of the three kinds of reservoir rock cores. The CT images show that no cracks exist in the specimens before the hydraulic fracturing experiments. Compared with sandstone and shale cores, the heterogeneity of granite cores is quite obvious, as seen in Figure 4c.

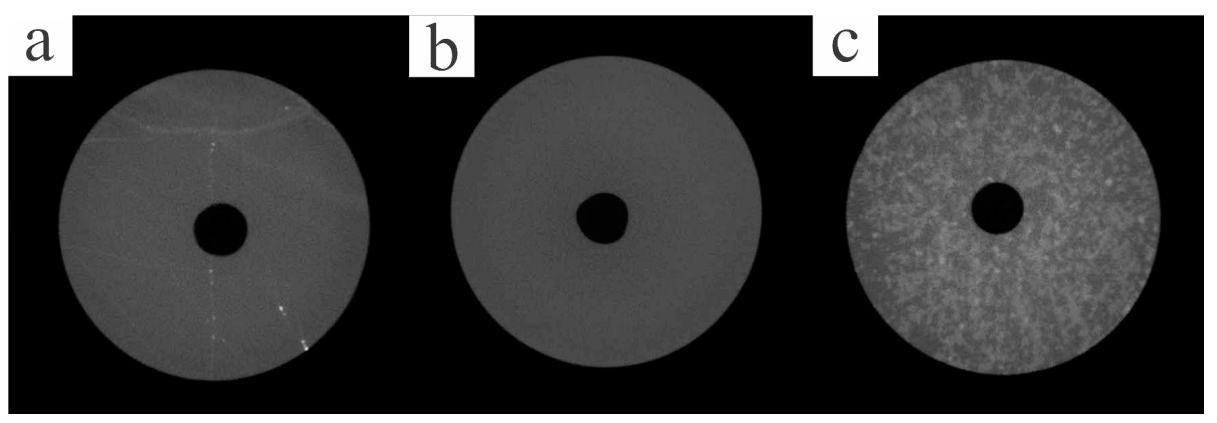

Figure 4. CT scanning images of sandstone (a); shale (b); and granite (c) before hydraulic fracturing.

\subsection{Experimental Monitoring of Hydraulic Fracturing}

The breakdown pressure determined from the experiments is related to the mechanical properties of the sample. Two mechanical parameters were tested: indirect tensile strength $\mathrm{T}_{0}$ (from Brazilian tests) and uniaxial compressive strength $\mathrm{C}_{0}$ (from UCS tests). The results for all the rock property tests and mechanical strength parameters are shown in Table 1 . Note that the values are the average of the corresponding testing method.

Table 1. Sample characteristics.

\begin{tabular}{ccccccc}
\hline \multirow{2}{*}{ Rock Type } & $\begin{array}{c}\text { Properties } \\
\text { Blane Angle }\end{array}$ & $\begin{array}{c}\text { Density } \\
\left(\mathbf{g} / \mathbf{c m}^{\mathbf{3}}\right)\end{array}$ & $\begin{array}{c}\text { Average P Wave } \\
\text { Velocity (m/s) }\end{array}$ & $\begin{array}{c}\text { Uniaxial } \\
\text { Compressive } \\
\text { Strength (MPa) }\end{array}$ & $\begin{array}{c}\text { Tensile } \\
\text { Strength } \\
(\mathbf{M P a})\end{array}$ & $\begin{array}{c}\text { Breakdown } \\
\text { Pressure } \\
\mathbf{( M P a )}\end{array}$ \\
\hline \multirow{5}{*}{ Shale } & $0^{\circ}$ & 2.60 & 4138 & 125 & 7.07 & 54.56 \\
& $30^{\circ}$ & 2.66 & 4293 & 45 & 5.63 & 42.29 \\
& $45^{\circ}$ & 2.61 & 4256 & 72 & 4.35 & 49.86 \\
& $60^{\circ}$ & 2.64 & 4377 & 90 & 3.49 & 46.82 \\
Granite & $90^{\circ}$ & 2.62 & 4543 & 151 & 3.09 & 39.14 \\
\hline Sandstone & $\mathrm{N} / \mathrm{A}$ & 2.78 & 5744 & 101.7 & 9.7 & 42 \\
\hline
\end{tabular}


Figure 5a-g shows the curves of pump pressure versus time during the hydraulic fracturing process under the same confining pressure $(20 \mathrm{MPa})$, axial stress $(25 \mathrm{MPa})$, and injection rate $(0.2 \mathrm{~mL} / \mathrm{s})$. The fluid injection with a constant flow rate brought about an increase in wellbore pressure, peaking at the breakdown pressure, and made the samples fail. It can be seen from the curve shown in Figure 5, at the beginning of the fluid injection, the wellbore pressure was kept at zero. Then it experienced a dramatic increase until peaking at the breakdown pressure. At the same time, the radial displacement increased sharply because of the tensile failure, a rapid increase of the confining pressure can also be seen. These two signals can be interpreted as the initial fracturing. As soon as the samples were broken by the high pressure induced by the fluid injection, the wellbore pressure decayed due to the high permeation. After the sample was fractured, the fluid injection was halted. The confining pressure and axial stress will adjust themselves to an equilibrium state eventually. The pressure equilibrium indicates the communication between the internal and external fluids as a result of the formation/propagation of hydraulic fractures.

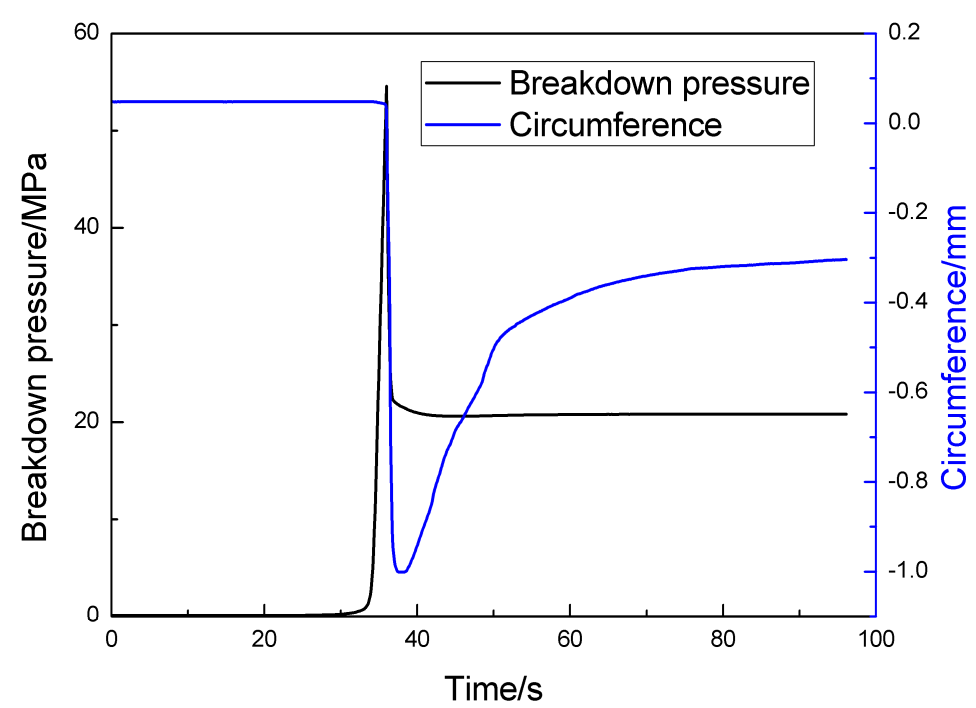

(a)

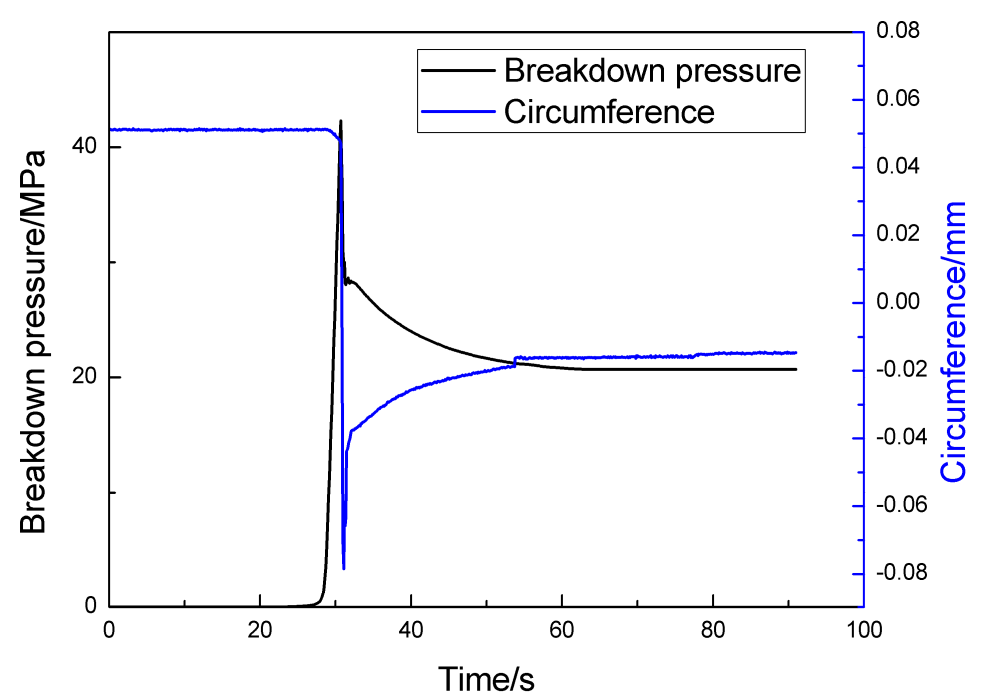

(b)

Figure 5. Cont. 


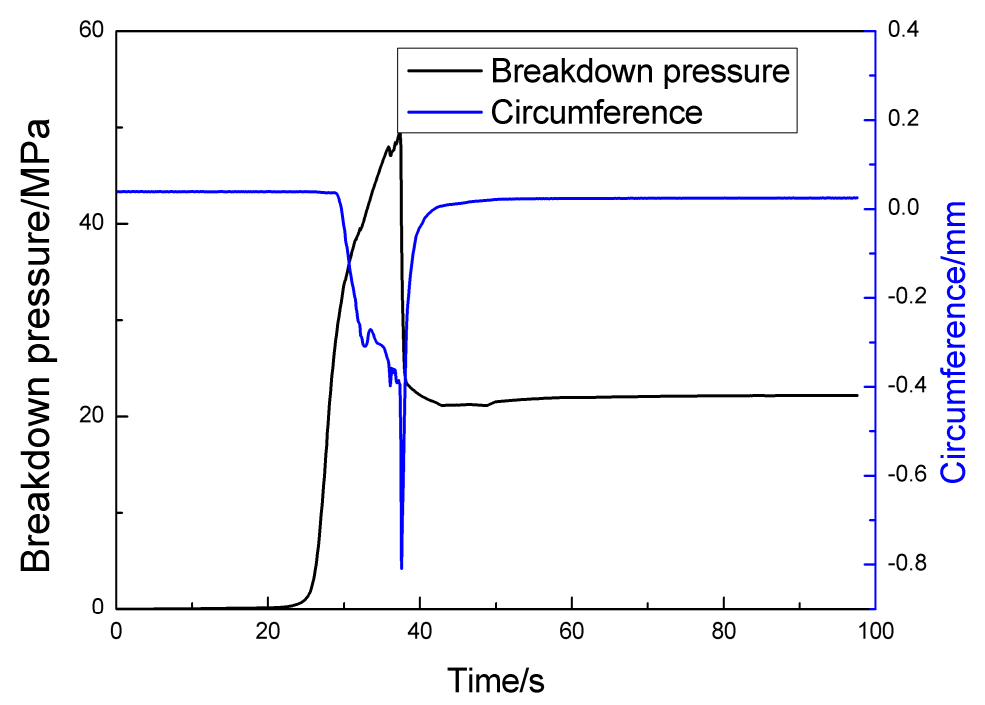

(c)

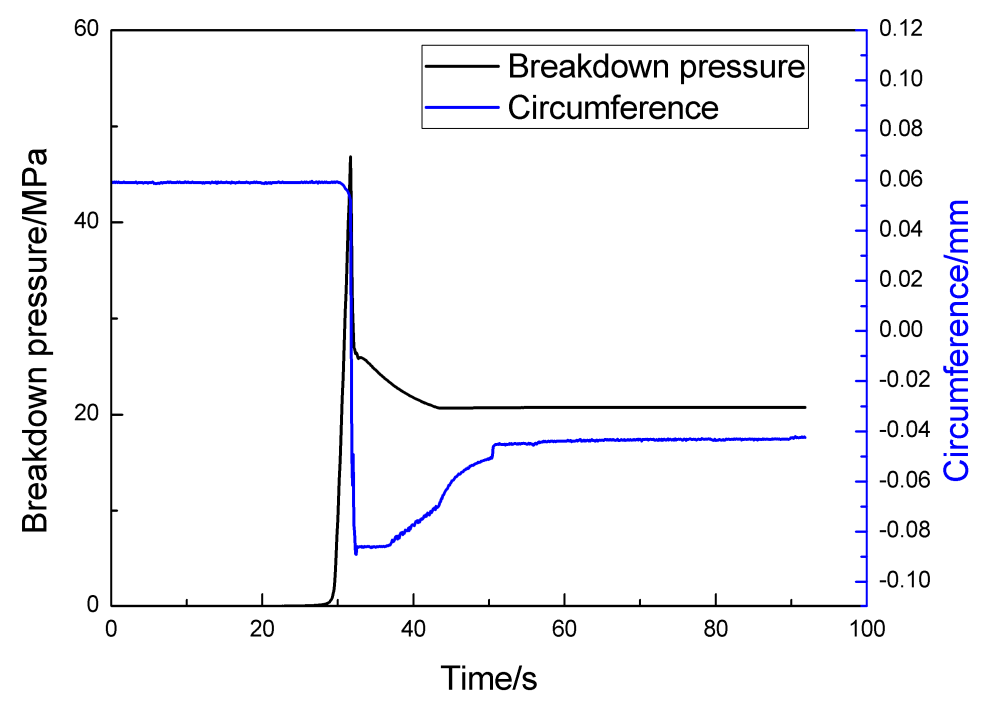

(d)

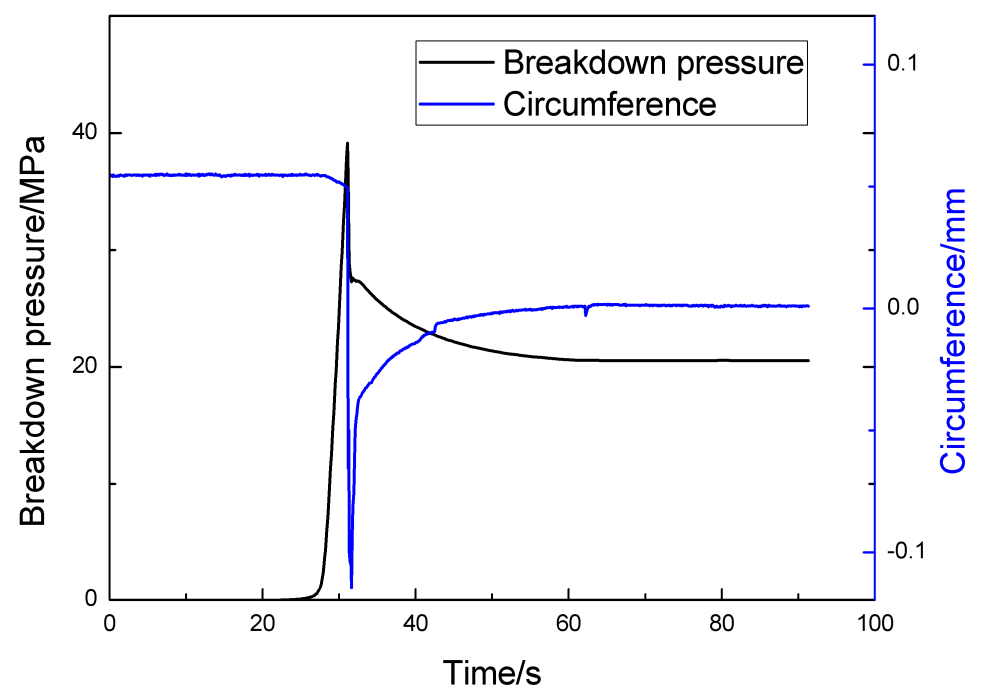

(e)

Figure 5. Cont. 


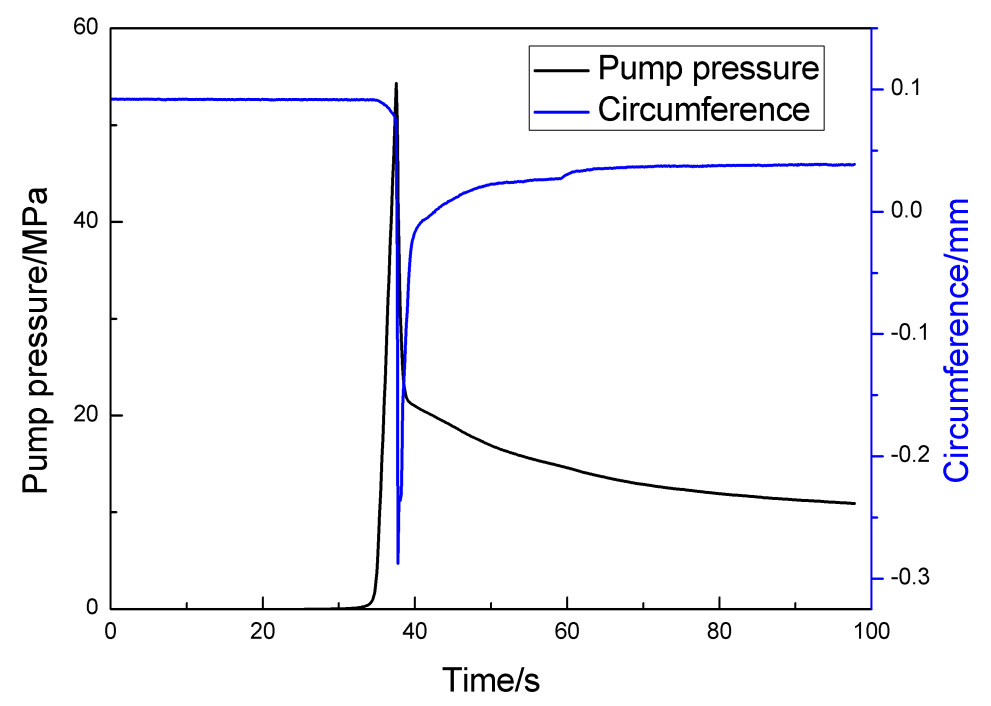

(f)

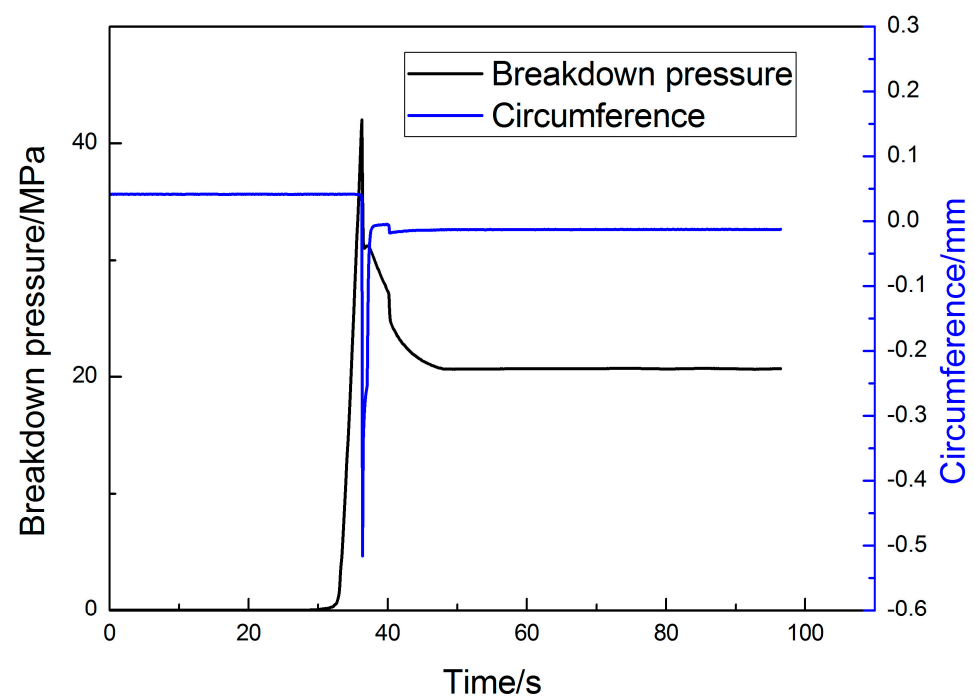

(g)

Figure 5. (a) Pump pressure and circumference monitoring of shale core 1 (bedding plane angle: $0^{\circ}$ ); (b) Pump pressure and circumference monitoring of shale core 2 (bedding plane angle: $30^{\circ}$ ); (c) Pump pressure and circumference monitoring of shale core 3 (bedding plane angle: $45^{\circ}$ ); (d) Pump pressure and circumference monitoring of shale core 4 (bedding plane angle: $60^{\circ}$ ); (e) Pump pressure and circumference monitoring of shale core 5 (bedding plane angle: $90^{\circ}$ ); (f) Pump pressure and circumference monitoring of sandstone core; (g) Pump pressure and circumference monitoring of granite core.

In Figure 6, the relationships between breakdown pressure and $P$ wave velocity are clearly shown. Combining it with Table 1, among these five samples with different bedding plane angles $\left(0^{\circ}, 30^{\circ}\right.$, $\left.45^{\circ}, 60^{\circ}, 90^{\circ}\right)$, the velocity is the lowest $\left(0^{\circ}: 4138 \mathrm{~m} / \mathrm{s}\right)$, the breakdown pressure is the highest one $(54.56 \mathrm{MPa})$, the velocity is the highest $\left(90^{\circ}: 4543 \mathrm{~m} / \mathrm{s}\right)$, the breakdown pressure is the lowest one (39.14 MPa). It is obvious that the variation of breakdown pressures with bedding plane angles is nearly opposite to the $\mathrm{P}$ wave velocities, as shown in Figure 6. 


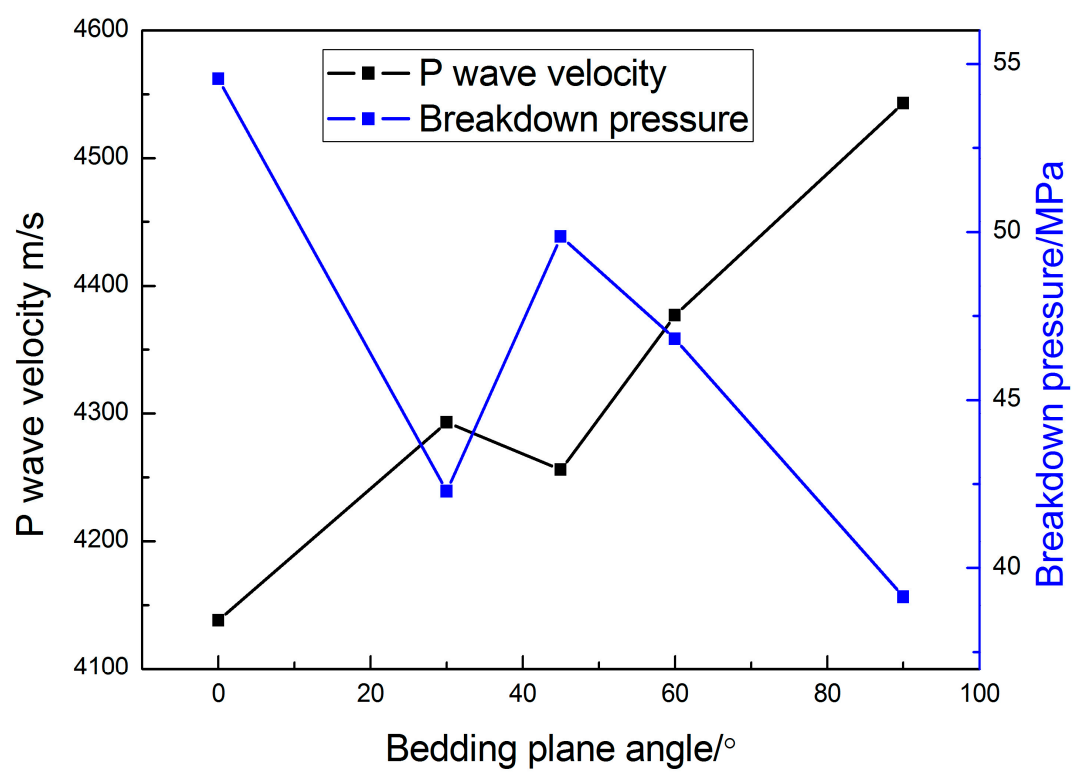

Figure 6. P wave velocity and breakdown pressure of shale samples with different bedding plane angles.

\subsection{Observations of the Induced Cracks}

The fracture networks provide the pathway for methane and fracturing fluid. The distribution of induced hydraulic fractures is of vital importance to the evaluation of hydraulic fracturing operation. The length, height and morphology—especially the location of the induced cracks-are important parameters for the assessment of fracturing results and the investigation of crack extension patterns. In this section, microscopic and macroscopic observations of the cracks in the fractured rock cores are illustrated. The CT scanner was also employed to acquire the spatial distribution of hydraulic fractures in fractured sandstone, shale, and granite cores. The different crack extension patterns in sandstone, shale, and granite cores were analyzed. The results provide a novel insight into the crack extension patterns in different reservoir formations.

\subsubsection{Macro-Observation of Induced Cracks}

In this experiment, the axial stress is the maximum principal stress. Based on the Hubbert and Willis $(\mathrm{H}-\mathrm{W})$ hydraulic fracturing criterion, the hydraulic fracture evolves perpendicular to the local minimum principal stress at the borehole in the sandstone, shale, and granite cores. The cracks are visible in the fractured sandstone and shale cores. The macro-observation of fractured shale cores indicates that the different crack patterns observed in shale reservoir and the bedding planes play an important role in the propagation of the hydraulic fractures. In the fractured granite cores, the hydraulic fractures are not visible from the surface of the fractured samples.

\subsubsection{Micro-Observation of Induced Cracks}

As a non-destructive technology to obtain the internal structure of rock materials, $\mathrm{X}$-ray computer tomography (CT) provides an ideal method to study the spatial distribution of induced cracks in fractured rock cores. Therefore, a high precision 16 bit micro-focus X-ray CT scanning device was employed to conduct the X-ray microtomography tests (XMT) of the fractured sandstone, shale, and granite cores. XMT scanning was performed at $320 \mathrm{keV}$ and $3 \mathrm{~mA}$ for optimum image quality and contrast. The specimens were rotated continuously during the XMT scanning with momentary stops to collect each projection and minimize the artifacts with an image voxel size of $30 \mu \mathrm{m}$. Every sample was scanned to obtain a CT slice with a thickness of $0.9 \mathrm{~mm}$ along the height from top to bottom, providing 100 slices for each sample. 
The grey levels measure the density distribution in the sample due to the amount of X-ray absorption. The gray level of every pixel changes between 0 and 255, different grey levels present different densities, the lighter grey levels reflect higher density, conversely, the darker grey levels reflect lower density. In Figure 7a-g, four typical CT images were given out (slices 20, 40, 60, and 80) for each specimen fractured by high pressure injection (shale $(a-e)$, sandstone $(\mathrm{f})$, and granite $(\mathrm{g})$ ). The red dash lines in Figure 7 represent the hydraulic fractures.

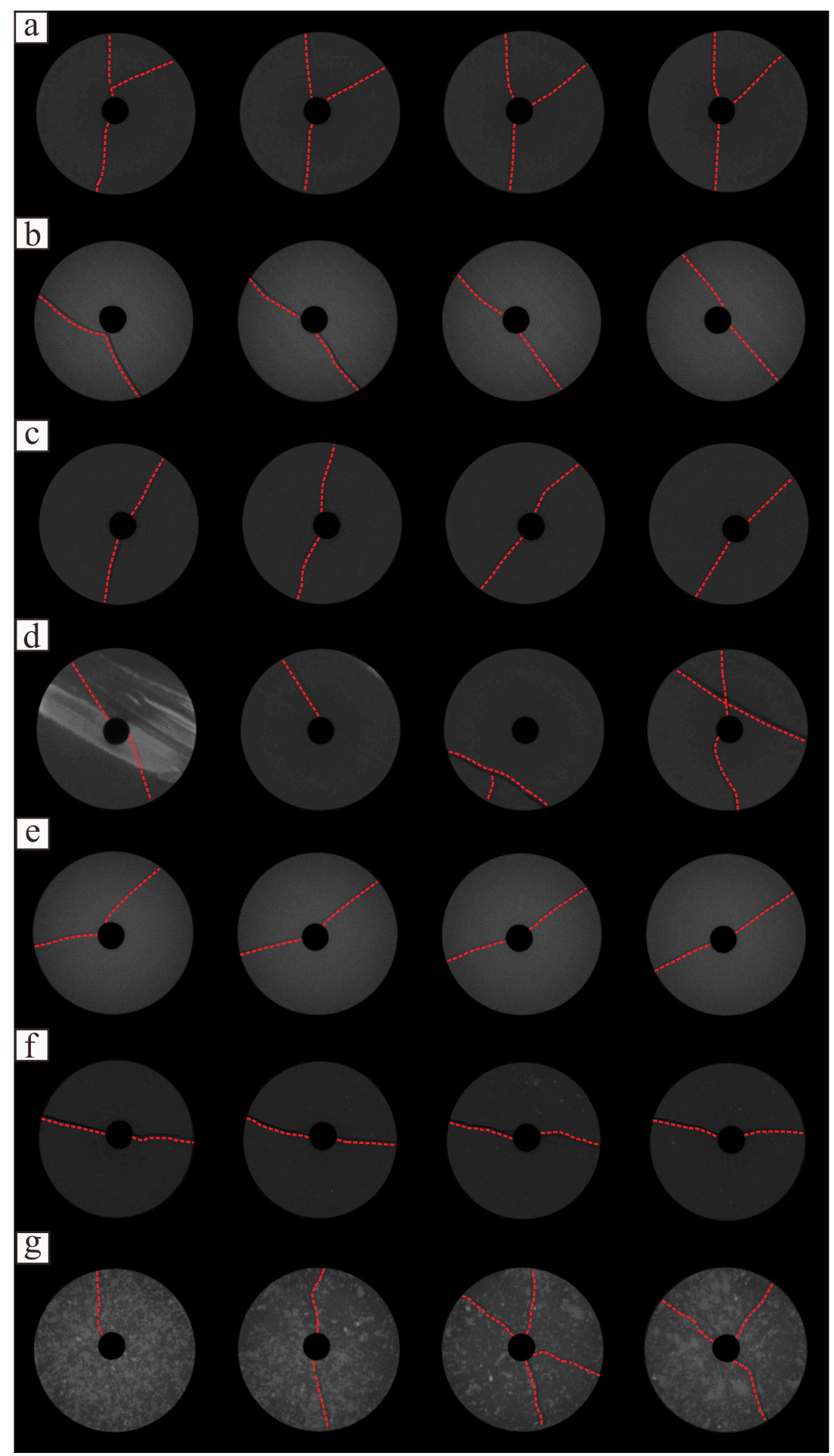

Figure 7. Typical CT scanning images of fractured shale (a-e); sandstone (f) and granite cores $(\mathbf{g})$ CT scanning showing a vertical slice through the middle of the sample. 


\subsection{Crack Extension Patterns in Different Rock Cores}

\subsubsection{Hydraulic Fracture Propagation Pattern in Sandstone}

To study the effects of the anisotropy of shale and heterogeneity of granite on hydraulic fracture propagation, sandstone cores were selected as a reference because of its lower anisotropy and heterogeneity. According to Hubbert and Willis (H-W) hydraulic fracturing criterion [28], the hydraulic fractures will initiate at the wellbore, and then propagate along the maximum principal stress direction. The micro-observation of hydraulic fractures in sandstone cores also demonstrates the fracture propagation pattern. The fractures are typical symmetrical cracks. In addition, it can be seen from the CT scanning results, as shown in Figure 7, that some micro-cracks were induced near the injection hole. It can be seen from Figure $5 \mathrm{f}$ that the breakdown pressure of sandstone in the experimental conditions set in our test is about $54 \mathrm{MPa}$.

\subsubsection{Hydraulic Fracture Propagation Pattern in Shale}

In Figure 6, CT scanning results of the fractured shale cores show the distribution of hydraulic fractures. The cracks are not simple symmetrical cracks as that in fractured sandstone. In shale core 1 (bedding plane angle: $0^{\circ}$ ), except a pair of symmetrical cracks, another crack was induced by the fracturing fluid. While at the top of shale cores 2 and 5 (bedding plane angles: $30^{\circ}$ and $90^{\circ}$ ), the cracks do not connect with the injection hole. In addition, in the fractured shale core 4 (bedding plane angle: $60^{\circ}$ ), cracks exist along a bedding plane and two cracks were induced from the injection hole. Compared to sandstone, the unique internal structure of shale plays an important role in the hydraulic fracture propagation process. The bedding planes could be regarded as weak planes. The hydraulic fracture will initiate at well bore, when the hydraulic fracture encounters a relatively weak bedding plane, three forms of fracture morphology could be observed. The crack may propagate along the bedding plane, across the bedding plane or be arrested by the bedding plane. The fractures were initially identified by naked eye and highlighted by hand with black dashed lines in Figure 7 . In the studies conducted by Olson et al. [29], the relationship between natural fractures and hydraulic factures can be classified into three behaviors: propagating along, across, and arresting the bedding planes. In some prospects, the natural fractures and relatively weak bedding planes can both be seen as weak planes existing in the shale formation, so the results seem to be very reasonable. In addition, the micro-observation of hydraulic fractures in fractured shale cores can demonstrate it.

\subsubsection{Hydraulic Fracture Propagation Pattern in Granite}

The hydraulic fracture extension pattern in granite cores is different to that in sandstone and shale cores. The cracks in fractured granite cores are not clearly visible to the naked eye, so the microscope was employed to obtain the crack geometry. Figure 8 shows the detailed features of hydraulic fractures. In addition, the CT scanning images display the crack distribution in fractured granite cores, as shown in Figure 6g. Due to the end effect, no cracks were induced at the top of the sample. These CT scanning slices indicate that the hydraulic fracturing operation induces two to four cracks. As aforementioned, the grey levels measure the density distribution in the sample due to the amount of $\mathrm{X}$-ray absorption. The gray level of every pixel changes between 0 and 255, different grey levels present different densities, the lighter grey level reflects higher density, conversely, the darker grey level reflects lower density. In Figure 9, the hydraulic fractures and the hard grain adjacent to them were marked to emphasize the relationship between fracture pathway and the grain distribution. The CT scanning results shown in Figure 10 indicate that the cracks do not propagate across the harder grain. The pathway of hydraulic fractures clearly shows that they will propagate along the boundary of the grains when they encounter the hard grains. 


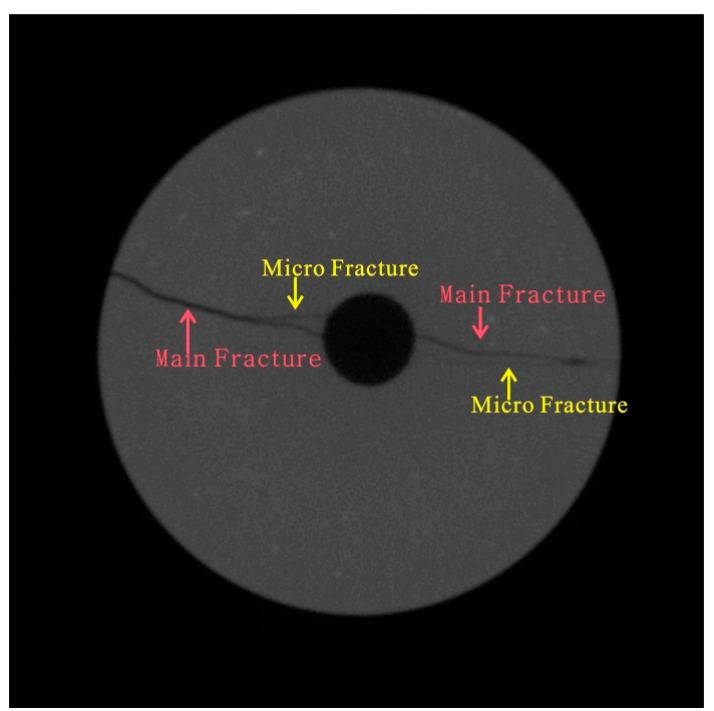

Figure 8. Typical CT image of fractured sandstone core, main fracture and micro fracture.

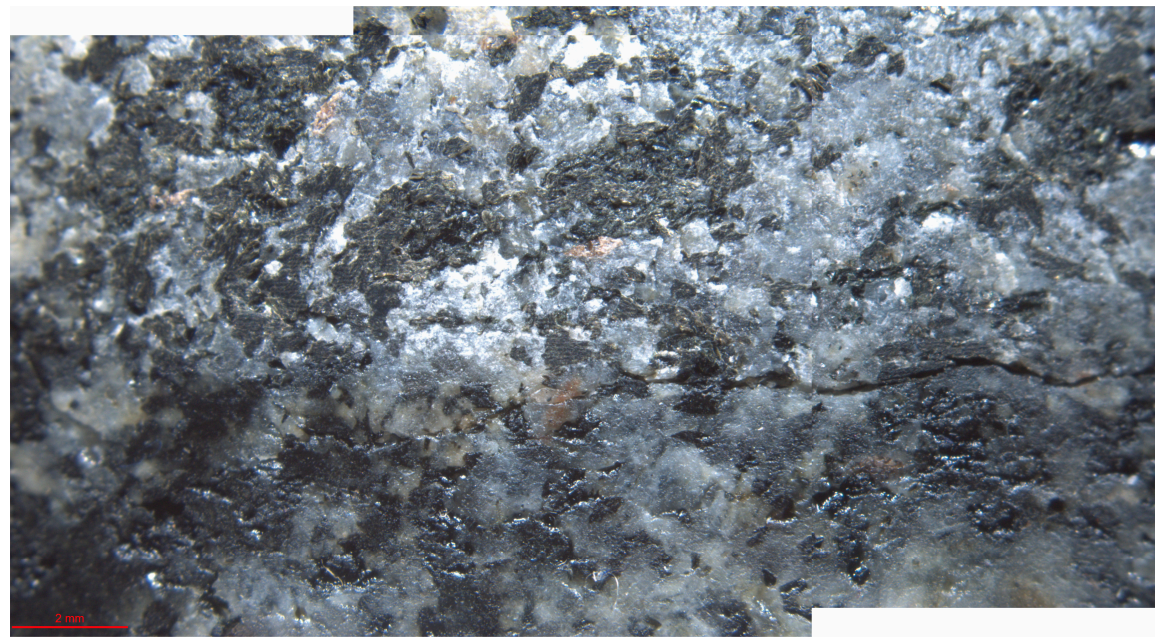

Figure 9. Detailed hydraulic fracture in fractured granite core made using microscope.

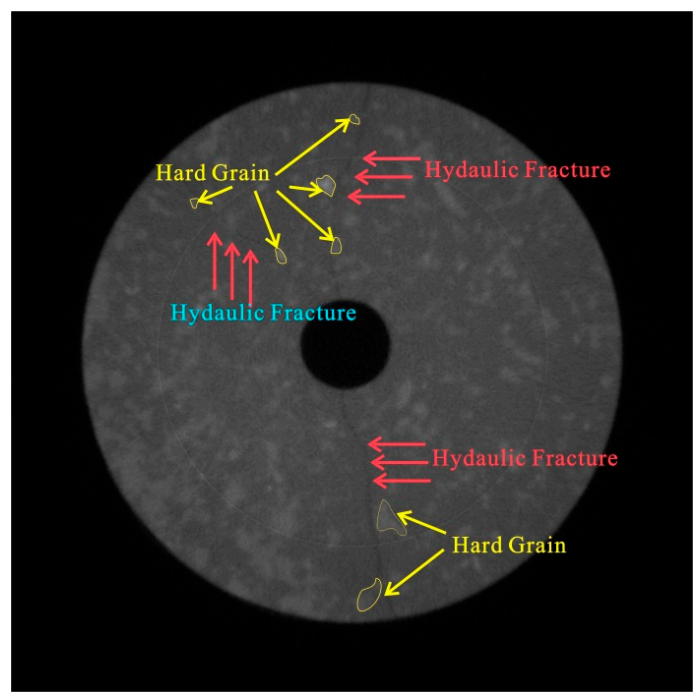

Figure 10. Typical CT image of fractured granite core. 


\subsubsection{Tortuosity Comparison of the Fractures in Sandstone, Shale, and Granite}

As discussed before, the morphology of hydraulic fractures in different fractured rock cores is different. To describe the hydraulic fractures quantitatively, tortuosity was selected as a parameter. According to a study by Chen and Nagaya [30], the tortuosity was defined as the total fracture length along a pathway divided by the direct length of the two ends of a fracture. In our study, the CT scanning results of fractured rock cores were used for the tortuosity quantification of the fractures. As mentioned in Section 3.3.2, the black pixels constitute the fractures in matching CT images. By extracting these black pixels, the data of fracture distribution could be obtained. By digital picture processing technique, the number of pixels occupied by each fracture in the CT images can be computed. Hence, the total length of the fracture along its pathway was obtained based on the relationship between the black pixel number and the fracture length. The tortuosity of every fracture was calculated based on the CT scanning results of the fractured sandstone, shale, and granite cores. The results demonstrated that the tortuosity of fractures in the fractured sandstone and shale cores were quite close, ranging from 1 to 1.1. However, the fractures in the fractured granite core are more tortuous than that in the fractured sandstone and shale cores, the fracture tortuosity ranges from 1.2 to 1.3. It indicates that the hydraulic fracture propagation pattern in granite is more complex than in sandstone and shale. The grains in granite play an important role in the fracture extension pathway. The fracture tortuosity results from the correlation of grains and pore structure in granite. During the propagation of a fracture in a rock, it may encounter a mechanical heterogeneity, while the heterogeneity will modify the stress field near the crack tip and the direction of fracture propagation may be affected. In Renard's study (2009), the roles of local mechanical variations (pores) were also demonstrated.

\section{Conclusions}

The economic viability of developing shale gas and geothermal resources largely depends on effective hydraulic fracture operation. Hydraulic fracturing has become a major technology to enable the commercial development of shale gas. In this article, a series of hydraulic fracturing experiments with sandstone, shale, and granite cores were performed. A CT scanner was used to acquire the information of spatial distribution of hydraulic fractures. The effects of initial heterogeneities on the propagation of hydraulic fractures were shown. The following conclusions can be drawn:

(1) The initial heterogeneities in rock materials—such as the laminated structure of shale, and the grain boundaries and pores in granite-play an important role in the propagation of hydraulic fractures. When the hydraulic fracture encounters a relative bedding plane in shale, the fracture may propagate along or across the bedding plane, or be arrested by it. Some micro-cracks were induced around the injection hole in the sandstone core.

(2) CT scanning experiments demonstrate the spatial distribution of hydraulic fractures in fractured sandstone, shale, and granite cores. The crack extension in sandstone, shale, and granite cores are extremely different.

(3) The results demonstrate that the tortuosity of fractures in fractured sandstone and shale cores are quite close, ranging from 1 to 1.1. However, the fractures in fractured granite core are more tortuous than that in fractured sandstone and shale cores, the fracture tortuosity ranges from 1.2 to 1.3. This may result from the different structure (initial heterogeneity) of the rocks.

Acknowledgments: The authors would like to thank the Editor and the anonymous reviewers for their helpful and constructive comments. This work is supported by the National Natural Science Foundation of China (Grant No. 41272351, 41227901, and 41572310) and the Strategic Priority Research Program of the Chinese Academy of Sciences (Grant No. XDB10030301 and XDB10030304). The authors also would like to particularly thank Songbo Yu and Guanghui Tian (Tongji University, China) for their consistent support, patience, and guidance throughout the experiment procedure.

Author Contributions: The four authors contributed equally to the present paper. Experiments were performed by Xiaole Wan and Chong Lin. Jianming He and Chong Lin analyzed the data and wrote the paper. General supervision was provided by Xiao Li. All authors have read and approved the final manuscript. 
Conflicts of Interest: The authors declare no conflict of interest.

\section{References}

1. The Future of Geothermal Energy: Impact of Enhanced Geothermal Systems (EGS) on the United States in the 21st Century. Available online: https://www1.eere.energy.gov/geothermal/pdfs/future_geo_energy.pdf (accessed on 6 October 2016).

2. Lamont, N.; Jessen, F.W. The Effects of Existing Fractures in Rocks on the Extension of Hydraulic Fractures. J. Pet. Technol. 1963, 15, 203-209. [CrossRef]

3. Blanton, T. An Experimental Study of Interaction between Hydraulically Induced and Pre-Existing Fractures. Soc. Pet. Eng. 1982. [CrossRef]

4. Warpinski, N.R.; Teufel, L.W. Influence of geologic discontinuities on hydraulic fracture propagation (includes associated papers 17011 and 17074). J. Pet. Technol. 1987, 39, 209-220. [CrossRef]

5. Lhomme, T.P.; de Pater, C.J.; Helfferich, P.H. Experimental study of hydraulic fracture initiation in Colton sandstone. In Proceedings of the SPE/ISRM Rock Mechanics Conference, Irving, TX, USA, 20-23 October 2002.

6. Gale, J.F.; Reed, R.M.; Holder, J. Natural fractures in the Barnett Shale and their importance for hydraulic fracture treatments. AAPG Bull. 2007, 91, 603-622. [CrossRef]

7. Zhou, J.; Chen, M.; Jin, Y.; Zhang, G.Q. Analysis of fracture propagation behavior and fracture geometry using a tri-axial fracturing system in naturally fractured reservoirs. Int. J. Rock Mech. Min. 2008, 45, 1143-1152. [CrossRef]

8. Dehghan, A.N.; Goshtasbi, K.; Ahangari, K.; Jin, Y. Experimental investigation of hydraulic fracture propagation in fractured blocks. Bull. Eng. Geol. Environ. 2015, 74, 887-895. [CrossRef]

9. Liu, Z.; Chen, M.; Zhang, G. Analysis of the influence of a natural fracture network on hydraulic fracture propagation in carbonate formations. Rock Mech. Rock Eng. 2014, 47, 575-587. [CrossRef]

10. Chuprakov, D.; Melchaeva, O.; Prioul, R. Injection-sensitive mechanics of hydraulic fracture interaction with discontinuities. Rock Mech. Rock Eng. 2014, 47, 1625-1640. [CrossRef]

11. Liu, E. Effects of fracture aperture and roughness on hydraulic and mechanical properties of rocks: Implication of seismic characterization of fractured reservoirs. J. Geophys. Eng. 2005, 2, 38-47. [CrossRef]

12. Guo, T.; Zhang, S.; Qu, Z.; Zhou, T.; Xiao, Y.; Gao, J. Experimental study of hydraulic fracturing for shale by stimulated reservoir volume. Fuel 2014, 128, 373-380. [CrossRef]

13. Fan, T.G.; Zhang, G.Q. Laboratory investigation of hydraulic fracture networks in formations with continuous orthogonal fractures. Energy 2014, 74, 164-173. [CrossRef]

14. Bennour, Z.; Ishida, T.; Nagaya, Y.; Chen, Y.; Nara, Y.; Chen, Q.; Sekine, K.; Nagano, Y. Crack Extension in Hydraulic Fracturing of Shale Cores Using Viscous Oil, Water, and Liquid Carbon Dioxide. Rock Mech. Rock Eng. 2015, 48, 1463-1473. [CrossRef]

15. Scholz, C.H. Experimental study of the fracturing process in britle rocks. J. Geophys. Res. 1968, 88, 555-568.

16. Renard, F.; Bernard, D.; Desrues, J.; Ougier-Simonin, A. 3D imaging of fracture propagation using synchrotron X-ray microtomography. Earth Planet. Sci. Lett. 2009, 286, 285-291. [CrossRef]

17. Chitrala, Y.; Moreno, C.; Sondergeld, C.H.; Rai, C.S. Microseismic mapping of laboratory induced hydraulic fractures in anisotropic reservoirs. In Proceedings of the Tight Gas Completions Conference, San Antonio, TX, USA, 2-3 November 2010.

18. Stanchits, S.; Mayr, S.; Shapiro, S.; Dresen, G. Fracturing of porous rock induced by fluid injection. Tectonophysics 2011, 503, 129-145. [CrossRef]

19. Brenne, S.; Molena, M.; Stöckert, F.; Alber, M. Hydraulic and sleeve fracturing laboratory experiments on 6 rock types. In Proceedings of the International Society for Rock Mechanics (ISRM) International Conference for Effective and Sustainable Hydraulic Fracturing, Brisbane, Australia, 20-22 May 2013.

20. Li, X.; Feng, Z.; Han, G.; Elsworth, D.; Marone, C.; Saffer, D. Hydraulic Fracturing in Shale with $\mathrm{H}_{2} \mathrm{O}, \mathrm{CO}_{2}$ and $\mathrm{N}_{2}$. In Proceedings of the 49th US Rock Mechanics/Geomechanics Symposium, San Francisco, CA, USA, 28 June-1 July 2015.

21. Pradhan, S.; Stroisz, A.M.; Fjær, E.; Stenebråten, J.F.; Lund, H.K.; Sønstebø, E.F. Stress-Induced Fracturing of Reservoir Rocks: Acoustic Monitoring and $\mu$ CT Image Analysis. Rock Mech. Rock Eng. 2015, 48, 2529-2540. [CrossRef] 
22. Shao, H.; Kabilan, S.; Stephens, S.; Suresh, N.; Beck, A.N.; Varga, T.; Martin, P.F.; Kuprat, A.; Jung, H.B.; Um, W.; et al. Environmentally friendly, rheoreversible, hydraulic-fracturing fluids for enhanced geothermal systems. Geothermics 2015, 58, 22-31. [CrossRef]

23. Zhu, H.; Wang, Q.; Zhuang, X. A nonlinear semi-concurrent multiscale method for fractures. Int. J. Impact Eng. 2016, 87, 65-82. [CrossRef]

24. Zhuang, X.; Huang, R.; Liang, C.; Rabczuk, T. A coupled thermo-hydro-mechanical model of jointed hard rock for compressed air energy storage. Math. Probl. Eng. 2014, 2014, 179169. [CrossRef]

25. Ren, H.; Zhuang, X.; Cai, Y.; Rabczuk, T. Dual-horizon peridynamics. Int. J. Numer. Methods Eng. 2016, 108. [CrossRef]

26. Mighani, S.; Sondergeld, C.H.; Rai, C.S. Observations of tensile fracturing of anisotropic rocks. SPE J. 2016, 21, 1289-1301. [CrossRef]

27. Vernik, L.; Liu, X. Velocity anisotropy in shales: A petrophysical study. Geophysics 1997, 62, $521-532$. [CrossRef]

28. Hubbert, M.K.; Willis, D.G.W. Mechanics of hydraulic fracturing. Mem. Am. Assoc. Pet. Geol. 2013, 18, 153-163.

29. Olson, J.E.; Bahorich, B.; Holder, J. Examining Hydraulic Fracture: Natural Fracture Interaction in Hydrostone Block Experiments. In Proceedings of the SPE Hydraulic Fracturing Technology Conference, The Woodlands, TX, USA, 6-8 February 2012.

30. Chen, Y.; Nagaya, Y.; Ishida, T. Observations of Fractures Induced by Hydraulic Fracturing in Anisotropic Granite. Rock Mech. Rock Eng. 2015, 48, 1455-1461. [CrossRef]

(C) 2016 by the authors; licensee MDPI, Basel, Switzerland. This article is an open access article distributed under the terms and conditions of the Creative Commons Attribution (CC-BY) license (http:/ / creativecommons.org/licenses/by/4.0/). 